\title{
Evaluating secondary school students' interest and conceptual understanding of circuits
}

\author{
Jan-Philipp Burde \\ University of Tübingen, Physics Education Research Group, Auf der Morgenstelle 14, Tübingen, Germany \\ Thomas Wilhelm ${ }^{1}$, Martin Hopf ${ }^{2}$, Lana Ivanjek ${ }^{2}$, Thomas Schubatzky ${ }^{3}$, \\ Claudia Haagen-Schützenhöfer ${ }^{3}$, Liza Dopatka ${ }^{4}$, and Verena Spatz ${ }^{4}$ \\ ${ }^{1}$ Goethe University, Department of Physics Education Research, Max-von-Laue-Str.1, Frankfurt a.M., Germany \\ ${ }^{2}$ University of Vienna, Austrian Educational Competence Centre Physics, Porzellangasse 4, Vienna, Austria \\ ${ }^{3}$ University of Graz, Regional Centre for Didactics of Physics, Universitätsplatz, 5, Graz, Austria \\ ${ }^{4}$ TU Darmstadt, Physics Education Research Group, Hochschulstrasse 12, Darmstadt, Germany
}

Electric circuits are an important element of physics classes in Austria, Germany, and most countries around the world. However, many students leave secondary school without having an adequate conceptual understanding of simple circuits. Voltage in particular has proven to be a difficult concept as students think of it as a property or component of the electric current. Furthermore, research has shown that girls tend to have a lower interest in physics than boys and that context-based physics instruction is a promising approach to increase girls' interest. However, it is unclear whether decades of research on students' conceptual difficulties e.g. with voltage as well as research into ways to promote girls' interest have had a significant impact on physics classrooms. For this reason, the conceptual understanding of electric circuits as well as the interest in physics of $N=1207$ traditionally taught students in Germany and Austria was assessed using a valid and reliable multiple-choice test. The empirical evaluation of the data shows that female students are still not as interested in physics as their male peers, despite achieving the same total learning gain in the multiple-choice test. An analysis of two items of the test instrument focusing on potential differences furthermore suggests that traditional instruction still fails to provide students with an adequate conceptual understanding of voltage as an independent physical quantity that refers to a difference in electric potential between two points in a circuit. These results highlight the need to develop research-based curricula on electric circuits that take into account the findings on students' interests and alternative conceptions. 


\section{INTRODUCTION}

Hardly any other discovery has had such a lasting impact on our modern civilization as the discovery of electricity. Nevertheless, research from the 1980s on students' alternative conceptions revealed that traditional instruction generally fails to provide students with an adequate conceptual understanding of simple DC circuits [1]. In particular, it was shown that many alternative conceptions often prevail even after instruction [2, 3]. Furthermore, research has shown that girls' interest in physics tends to be lower than boys' as traditional instruction does not take enough account of girls' interests $[4,5]$.

\section{BACKGROUND}

\section{A. Conceptual understanding of voltage}

Electric circuits represent a major challenge to most students in lower secondary schools [6]. Voltage in particular has proven to be a difficult concept as students often struggle to understand that it refers to two points in a circuit. Instead of conceptualizing voltage as an independent physical quantity, they believe that voltage is a property or component of the electric current [2]. In the light of these findings, physics education research has focused on the question how these conceptual difficulties with simple circuits can be explained. In the 1980s, for example, Cohen, Eylon and Ganiel argued that the traditional focus on current prevents a deeper understanding of the important role that potential differences play in electric circuits [7]. In German and Austrian textbooks, voltage is traditionally not introduced as a potential difference, but merely as "energy per charge" or "the cause of current flow". Consequently, it may be difficult for students to understand the relative character of voltage and that voltage as a potential difference always refers to two points in a circuit. However, given the importance of providing students with a robust concept of voltage, Gleixner [8] as well as Koller and Späth [9] developed a height analogy to visualize potential differences in circuits while a more recent curriculum developed by Burde and Wilhelm compares potential differences to air pressure differences [10]. All these approaches have proven to be comparatively effective in fostering a better conceptual understanding of circuits in a number of empirical studies $[8,11,12]$.

\section{B. Interest in physics}

In addition to systematically supporting students' conceptual understanding, promoting students' interest in physics is generally regarded an essential feature of high-quality physics teaching [13]. However, various studies come to the conclusion that girls are not as interested in physics as boys. This difference in interest is often attributed to the fact that traditional physics lessons do not take enough account of girls' interests. As a result, girls often struggle to see the relevance of what they learn in physics for their everyday lives $[4,5]$. A promising way to significantly raise girls' interest in physics is to embed physical topics in everyday contexts [4, 14-16]. In particular, it has long been known that teachers should include biological, medical, and environmental contexts in their lessons while also addressing the importance of physics for society in order to make the subject more meaningful and relevant to students - particularly to girls $[4,17]$. To what extent context-oriented teaching also contributes to a better conceptual understanding, however, is still unclear [18]. Nonetheless, the promotion of students' interest in physics and science in general should not be seen as a means to an end, i.e. fostering a better conceptual understanding, but as an educational goal in its own right in a world increasingly shaped by the natural sciences.

\section{RESEARCH QUESTIONS}

In order to address these issues, three German and two Austrian PER groups have launched the joint Design-Based Research (DBR) project EPo-EKo ("Electricity with Potential \& Electricity with Contexts" [spelled with a "K" in German]) [19]. The overall objective is to evaluate and improve the conceptual understanding of electric circuits in secondary schools as well as to raise students' interest in the topic by developing and evaluating new research-based curricula. Before investigating the effects of these new curricula, however, traditionally taught students' conceptual understanding of electric circuits and their interest in the topic was assessed. The teaching of these students was "traditional" in that teachers were not given any instructions as to how they should teach the topic "simple electric circuits", i.e. they taught in the same way as they had done in previous years using traditional textbooks. This allows to investigate whether students today still have significant conceptual difficulties (e.g. with the concept of potential difference) and whether girls are still significantly less interested in physics than boys despite decades of research by the PER community and years of in-service teacher training programs. The purpose of this paper is therefore to address the following three research questions:

1. Do girls today still show a significantly lower interest in physics than boys even though, based on earlier research findings, measures to promote their interest have long been known?

2. Do male and female students differ regarding their total learning gain, defined as the increase in their average ability estimate obtained by the Rasch analysis, when taught traditionally?

3. After traditional instruction, to what extent are secondary school students able to apply the concept of voltage to a simple resistive circuit? 


\section{SAMPLE AND METHOD}

A total of $N=1207$ students took part in the data collection using a pen-and-paper questionnaire. As part of this questionnaire, students were asked to self-report their gender. $51 \%$ of students stated that they were male and $49 \%$ stated that they were female. With the exception of three classes, which were already in 8th grade, all of the $N=59$ participating classes from 38 different secondary schools were in 7 th grade. Most of the participating schools were a so called "Gymnasium", which is a type of school aimed at higher ability students and usually covers grades 5 to $12 / 13$. Geographically, 12 schools were located in the German state of Hesse, 15 in the German state of Bavaria, 20 in the Austrian state of Styria and 12 in the Austrian state of Lower Austria. In order to measure the development of students' conceptual understanding as well as their interest in physics as a subject, a pretest-posttest design was used. The posttest was conducted directly after the topic "simple electric circuits" was taught, which was, on average, after 17.8 lessons $(S D=5.1)$ with a length of 45 minutes each.

In the pre- and posttest, the students' understanding of electric circuits was measured using a valid and reliable twotier multiple-choice test [20]. A sample item on voltage from the multiple-choice test illustrating its two-tier structure can be seen in Fig. 1. In the first tier of the questions, students have to choose an answer. In the second tier, they have to choose an explanation for their reasoning. The distractors on both tiers of the test are based on interviews with students in previous studies and typical alternative conceptions on electric circuits as they were repeatedly documented in various studies in recent decades $[1-3,6]$. One of the advantages of this two-tier structure is that it is easy to grade and still gives insight into students' reasoning. Students who choose a3 as their answer in the first tier and b1 as their explanation in the second tier, for example, are interpreted to believe that voltage is a property of the electric current. The whole test instrument was scored using a paired scoring model: if a correct answer was given with a correct explanation, the student was awarded with one point. In all other cases, zero points were given. Such an analysis minimizes false positive answers because an item is rated as correct only if the answer and the corresponding explanation are correct.

As the topic of electric circuits had not been covered before in any of the participating classes, the pretest consisted only of a partial set of 12 items, while the posttest consisted of 21 items. To evaluate the students' total learning gain, a Rasch analysis of the whole test instrument was conducted with the program " $R$ " using a dichotomous model in order to obtain linear measures for item difficulties [21]. The Rasch model is a probabilistic model that describes response patterns of examinees to individual items. It assumes that there exists a linear measure common to items and students: for items that measure is "item difficulty" $\left(D_{i}\right)$ and for students the measure is called "ability estimate" $\left(B_{n}\right)$ [22]. A more detailed introduction to the Rasch model can be found in [23]. The linear measures obtained by the Rasch analysis allow a com-

\begin{tabular}{|c|c|}
\hline Item 1 & $\begin{array}{l}\text { The switch between points } 1 \text { and } 2 \text { in the } \\
\text { circuit diagram below is closed. } \\
\text { What is the voltage between points } 1 \text { and } 2 \\
\left(V_{12}\right) \text { and } 2 \text { and } 3\left(V_{23}\right) \text { ? }\end{array}$ \\
\hline & $6 \mathrm{~V}^{\frac{+}{7}}$ \\
\hline a1 & $\mathrm{V}_{12}>\mathrm{V}_{23}$ \\
\hline a2 & $\mathrm{V}_{12}=6 \mathrm{~V}$ und $\mathrm{V}_{23}=0 \mathrm{~V}$ \\
\hline a3 & $\mathrm{V}_{12}=\mathrm{V}_{23}=6 \mathrm{~V}$ \\
\hline $\mathrm{a} 4$ & $\mathrm{~V}_{12}=\mathrm{V}_{23}=2 \mathrm{~V}$ \\
\hline \multirow[t]{2}{*}{ a5 } & $\mathrm{V}_{12}=0 \mathrm{~V}$ und $\mathrm{V}_{23}=6 \mathrm{~V}$ \\
\hline & How do you explain your reasoning? \\
\hline b1 & $\begin{array}{l}\text { The voltage is the same everywhere in the } \\
\text { circuit since the current is the same in the entire } \\
\text { circuit. }\end{array}$ \\
\hline $\mathrm{b} 2$ & $\begin{array}{l}\text { The voltage decreases with increasing distance } \\
\text { from the battery. }\end{array}$ \\
\hline b3 & The resistor consumes the voltage. \\
\hline b4 & $\begin{array}{l}\text { The wires have no resistance, so the entire } \\
\text { voltage of the battery is applied to the resistor. }\end{array}$ \\
\hline b5 & $\begin{array}{l}\text { The voltage is distributed evenly over the } \\
\text { entire circuit. }\end{array}$ \\
\hline
\end{tabular}

FIG. 1. Item 1 (translated from German) from the test instrument illustrating its two-tier structure. The correct answer (a5) and explanation (b4) are printed in bold.

parison of the "person abilities" by expressing the data of the pretest and posttest on the same scale [24]. Furthermore, the Rasch analysis examines the fit of the data to the model. Fit is understood as comparison of the differences between what is observed and what is expected by the Rasch model. The general rule of thumb is that items with infit and outfit MNSQ values between 0.7 and 1.3 have good model fit [22]. Based on the parameters of the test instrument on students' understanding of simple electric circuits $0.94<$ Infit $<1.09$ (EAPReliability $=0.71$ ) it can hence be concluded that it worked satisfactorily.

Students' conceptual understanding of voltage was assessed at the example of two items of the two-tier multiplechoice test. Both items examine whether students possess an adequate concept of voltage as an independent physical quantity that refers to a difference in electric potential between two points in a circuit (see Fig. 1 and Fig. 2). Item 1 asks for the voltage across a closed switch and across a resistor and item 2 shows an open circuit and the students' task is simply to identify the potential difference between the two unconnected wires. 


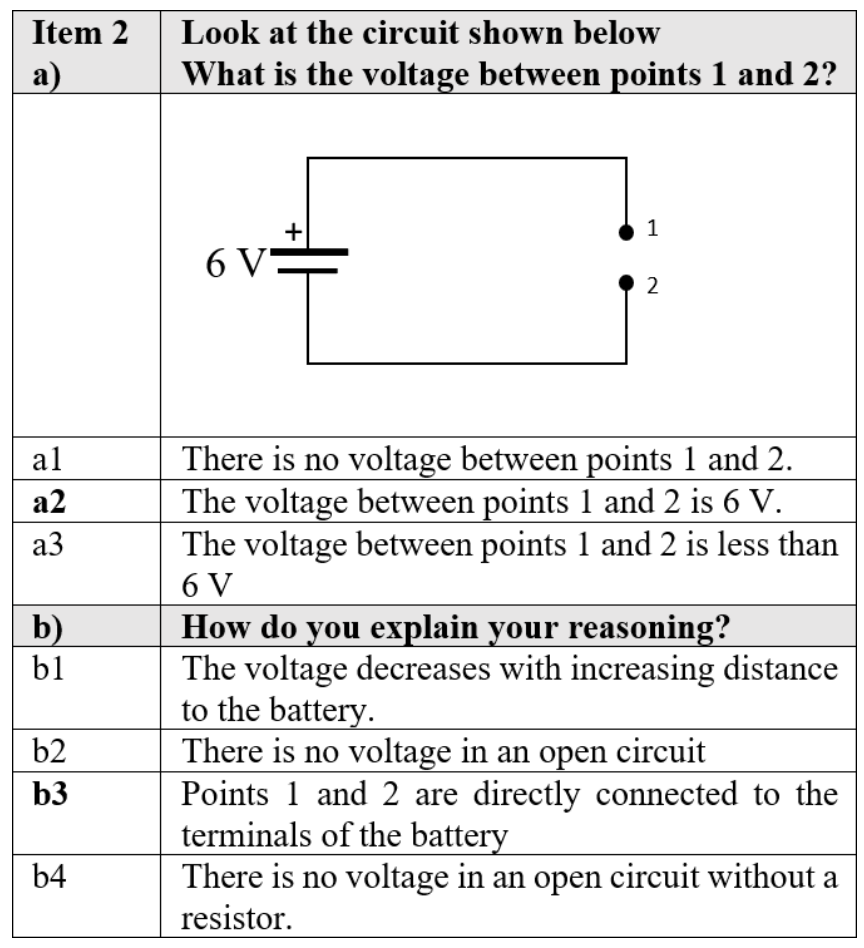

FIG. 2. Item 2 (translated from German) on voltage in an open circuit. The correct answer (a2) and explanation (b3) are printed in bold.

Students' interest was assessed on the basis of nine items, six of which were newly developed [25] and three of which came from the PISA study [26] (e.g. "I like reading about physics" or "I am interested in learning about physics"). These items were combined into the overall construct "interest in physics" [25]. Students were asked to respond to each of the questions using a five-point Likert scale with the categories "strongly agree", "agree", "neutral", "disagree", and "strongly disagree". Next, a Rasch analysis using a rating scale model was performed with the program "R" [21]. The parameters of the test on students' interest in physics indicate that it worked satisfactorily $(0.72<$ Infit $<1.21$, EAPReliability $=0.89$ ).

\section{EMPIRICAL RESULTS}

\section{A. Interest in physics}

Figure 3 shows students' interest in physics by gender and time of testing. Girls' interest in physics increases from $M=$ $1.60(S E=0.06)$ in the pretest to $M=1.65(S E=0.06)$ in the posttest, while it increases from $M=1.91(S E=0.06)$ in the pretest to $M=2.01(S E=0.06)$ in the posttest for boys. The main effects of students' gender, $\chi^{2}(1)=21.58, p<.001, d=$ .23 , and the time of testing (pretest vs. posttest), $\chi^{2}(1)=4.56$, $p<.03, d=.12$, on students' interest in physics are both sta-

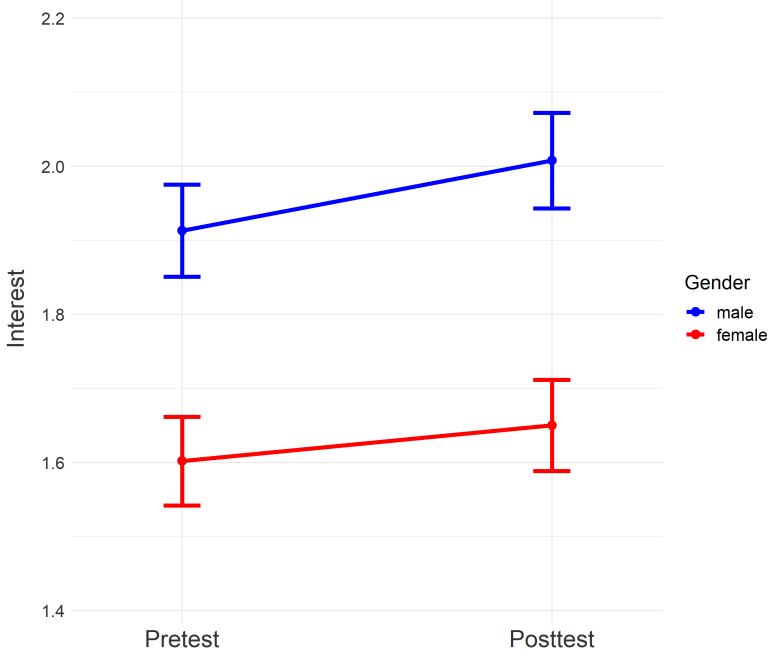

FIG. 3. Interest in physics by gender in the pretest and posttest based on a rating scale model. The error bars represent the standard error (SE). The higher the value, the higher the interest.

tistically significant. However, there is no interaction effect of the time of testing and students' gender on their interest in physics $\left(\chi^{2}(1)=0.77, p=.38, d=.05\right)$. It can therefore be concluded that girls still show a lower interest in physics than their male peers and that traditional instruction fails to reduce this gap, which is also reported in other studies [4].

\section{B. Total learning gain}

As illustrated in Fig. 4, there is a significant increase of the average students' conceptual understanding of simple electric circuits, measured here as the ability estimate in the conceptual knowledge test, for both male and female students. The ability estimate increases from $M=-0.54(\mathrm{SE}=0.04)$ in the pretest to $M=0.26$ ( $\mathrm{SE}=0.04)$ in the posttest for female students and from $M=-0.51(\mathrm{SE}=0.05)$ in the pretest to $M$ $=0.28(\mathrm{SE}=0.04)$ in the posttest for male students. Statistically, there is a main effect of the time of testing (pretest vs. posttest) on the estimated average person ability $\left(\chi^{2}(1)=\right.$ $444.29, p<.001, d=.99)$. However, there is no interaction effect of the time of testing and the students' gender on the average ability estimate $\left(\chi^{2}(1)=0.00, p=.99, d<.01\right)$, nor is there a main effect of the students' gender on the average ability estimate $\left(\chi^{2}(1)=1.51, p=.22, d=.05\right)$. It can therefore be concluded that girls, despite showing a significantly lower interest in physics than boys, still achieve the same learning gain as their male peers in traditional instruction of simple circuits in Austria and Germany. This represents an interesting finding as previous studies report that girls attain lower learning gains than boys [11,27]. 


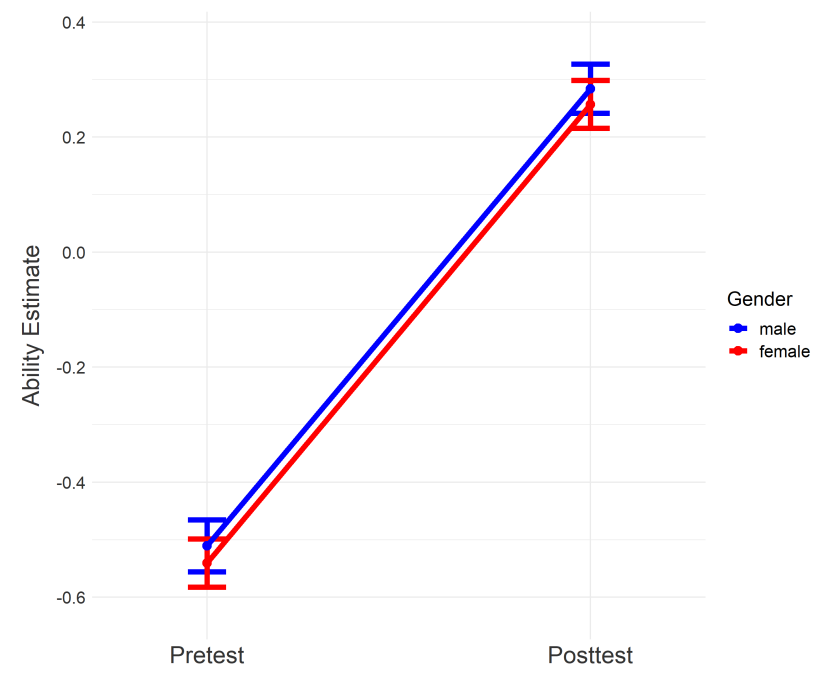

FIG. 4. Conceptual understanding, measured here as the ability estimate in the conceptual knowledge test, by gender in the pretest and posttest using Rasch scores. The error bars represent the standard error (SE). The higher the value, the better the conceptual understanding.

\section{Conceptual understanding of voltage}

As shown in Fig. 5 only $4 \%(S E=1 \%)$ of traditionally taught students provide a correct answer and a correct explanation for item 1 and only 7\% $(S E=1 \%)$ give a correct answer and a correct explanation for item 2. A plurality of $25 \%$ of all students chose a 3 or a 4 as their answer with b1 as their explanation for item 1 , indicating that these students consider voltage as a property of the electric current. For item 2 , the combination of answer and explanation chosen by $50 \%$ of the students is based on the statement "there is no voltage in an open circuit" on tier 2, which also suggests that students do not differentiate conceptually between current and voltage. Based on these results, it can be assumed that traditional instruction fails to provide students with an adequate conceptual understanding of voltage as an independent physical quantity that refers to a difference in electric potential between two points in a circuit.

\section{DISCUSSION AND OUTLOOK}

The findings presented in this paper clearly show that traditional instruction in Austria and Germany fails to provide students with an adequate conceptual understanding of voltage. Instead, the combination of answers chosen by many students suggests that voltage is often seen as a property of the electric current, which corresponds well with previous research findings on alternative conceptions $[2,7,11]$. Against the background of decades of research on the teaching and learning of electricity and the conceptual difficulties with voltage in particular, this represents a sobering finding. From a PER perspective, it could be argued that one of the reasons for these prevailing learning difficulties lies in the fact that insights into alternative conceptions have had little influence on secondary school physics classrooms.

Furthermore, our findings indicate that girls still show a significantly lower interest in physics than their male peers, which suggests that previous research findings into girls' interest may have had little influence on physics teaching in secondary schools in Austria and Germany. However, it is noteworthy that female students, despite being less interested in physics on average, achieve the same total learning gain as their male peers. Nonetheless, developing a research-based curriculum on electric circuits that takes into account previous research findings on students' interest represents a meaningful endeavor as increasing students' interest in physics is an educational goal in its own right and may, for example, encourage more girls to study physics or a physics related subject at college or university. The EPo-EKo project therefore aims to develop research-based curricula that improve students' conceptual understanding and that promote their interest in physics - especially among female students.

\section{ACKNOWLEDGMENTS}

This work was supported by the Deutsche Telekom Stiftung and Vector Stiftung. Their continuing support is gratefully acknowledged.

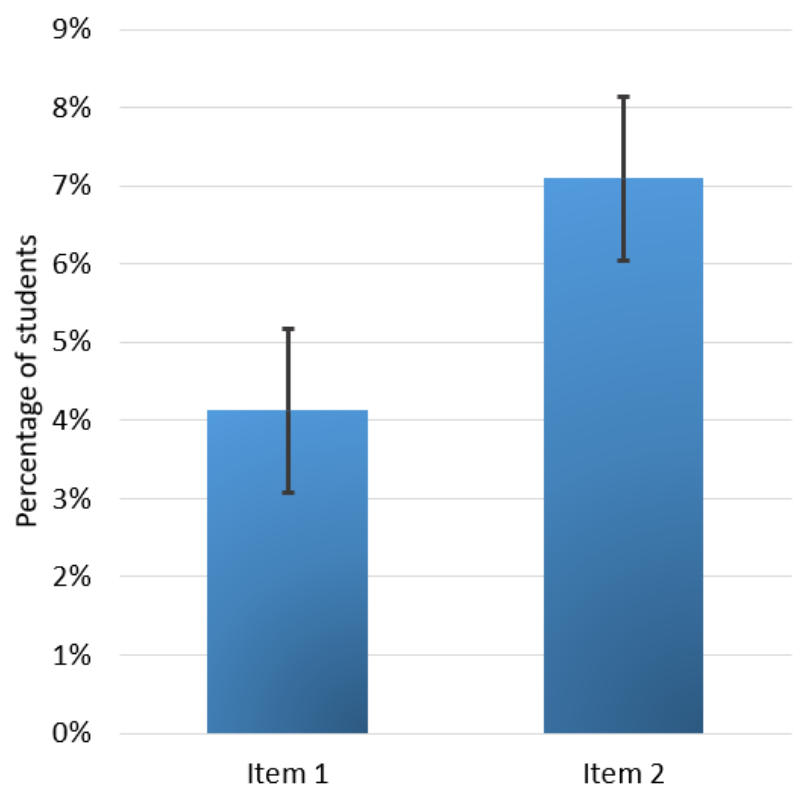

FIG. 5. Percentage of students giving correct answers with correct explanations for two items on potential differences in simple circuits after traditional instruction in the posttest (paired scoring model). The error bars represent the standard error (SE). 
[1] R. Duit, Bibliography - STCSE: Students' and Teachers' Conceptions and Science Education, available at: http://archiv.ipn.uni-kiel.de/stcse/ [last accessed: 03 Jun 2020].

[2] L.C. McDermott and P.S. Shaffer, Am. J. Phys. 60, 11 (1992).

[3] R. Duit, W. Jung, and C. v. Rhöneck (Eds.), Aspects of Understanding Electricity - Proceedings of an International Workshop. IPN-Arbeitsberichte (Schmidt \& Klaunig, Kiel, 1985).

[4] L. Hoffmann, P. Häußler, and M. Lehrke, Die IPNInteressenstudie Physik (IPN, Kiel, 1998).

[5] R. Millar, in Making it relevant: Context based learning of science, edited by P. Nentwig and D. Waddington (Waxmann Münster, New York, 2005).

[6] D.M. Shipstone, C.v. Rhöneck, W. Jung, C. Kärrqvist, J.-J. Dupin, S. Johsua, and P. Licht, Int. J. Sci. Math. Educ. 10, 303 (1988).

[7] R. Cohen, B. Eylon, and U. Ganiel, Am. J. Phys. 51, 407 (1983).

[8] C. Gleixner, Ph.D. thesis, LMU München, 1998.

[9] S. Späth, Zulassungsarbeit, LMU München, 2009.

[10] J.-P. Burde and T. Wilhelm, in Proceedings of the Physics Education Research Conference, 2017, edited by L. Ding, A.L. Traxler, and Y. Cao, p.68.

[11] J.-P. Burde, Konzeption und Evaluation eines Unterrichtskonzepts zu einfachen Stromkreisen auf Basis des Elektronengasmodells (Logos, Berlin, 2018).

[12] C. Waltner, S. Späth, D. Koller, and H. Wiesner, in GDCP Jahrestagung, 2009, edited by D. Höttecke, p.182.

[13] A. Krapp and M. Prenzel, Int. J. Sci. Educ. 33, 1 (2011).

[14] N. Finkelstein, J. Appl. Dev. Psychol. 27, 10 (2005).

[15] F. Lubben, J. Bennett, S. Hogarth, and A. Robinson, A systematic review of the effects of context-based and ScienceTechnology-Society (STS) approaches in the teaching of secondary science on boys and girls, and on lower-ability pupils, (University of London, London, 2005).
[16] R. Berger, ZfDN 8, 1 (2002).

[17] C. Schreiner and S. Sjøberg, Sowing the seeds of ROSE. Background, rationale, questionnaire development and data collection for ROSE (The Relevance of Science Education): a comparative study of students' views of science and science education (University of Oslo, Oslo, 2004).

[18] G. Taasoobshirazi and M. Carr, Educ. Res. Rev. 3, 3 (2008).

[19] C. Haagen-Schützenhöfer, J.-P. Burde, M. Hopf, V. Spatz and T. Wilhelm, in GIREP 2017 Selected Papers, edited by E. McLoughlin.

[20] L. Ivanjek, M. Hopf, J.-P. Burde, T. Wilhelm, L. Dopatka, V. Spatz, T. Schubatzky, and C. Haagen-Schützenhöfer, in GDCP Jahrestagung, 2018, edited by C. Maurer, p.209.

[21] R Development Core Team, $R$ : A language and environment for statistical computing (R Foundation for Statistical Computing, Vienna, 2008).

[22] X. Liu, Using and Developing Measurement Instruments in Science Education: A Rasch Modeling Approach (Information Age Publishing, Charlotte, NC, 2010).

[23] T. G. Bond and C. M. Fox, Applying the Rasch Model: Fundamental Measurement in the Human Sciences (Lawrence Erlbaum, Mahwah, NJ, 2001).

[24] W. J. Boone, J. R. Staver, and M. S. Yale, Rasch analysis in the human sciences (Springer, Dordrecht, 2014).

[25] L. Dopatka, V. Spatz, J.-P. Burde, T. Wilhelm, L. Ivanjek, M. Hopf, T. Schubatzky, and C. Haagen-Schützenhöfer, in Proceedings of the Physics Education Research Conference, 2020, edited by S. Wolf, M. Bennett, and B. Frank.

[26] A. Frey et al., PISA 2006 Skalenhandbuch: Dokumentation der Erhebungsinstrumente (Waxmann, Münster, 2009).

[27] J. Baumert et al., TIMSS - Mathematischnaturwissenschaftlicher Unterricht im internationalen Vergleich. Deskriptive Befunde (Leske \& Budrich, Opladen, 1997). 